\title{
Kinetics of Generation of Thermal Donors in Silicon of Stabilization of States of Fast-Diffusing Impurities
}

\author{
Shoikrom Askarov, ${ }^{1,}$, Bashirulla Sharipov ${ }^{1}$, Shokhista Saliyeva ${ }^{1}$, Abdulaziz Mavlyanov², \\ Solizhon Srazev ${ }^{3}$, Tuchi Toshboev ${ }^{3}$ \\ ${ }^{1}$ Department of Physics, Faculty of Mechanics, Tashkent State Technical University, Tashkent, Uzbekistan \\ ${ }^{2}$ Laboratory of Mining, Uzbek-Japan Innovation Centre of Youth, Tashkent State Technical University, Tashkent, Uzbekistan \\ ${ }^{3}$ Department of Condensed Matter Physics, Faculty of Physics, Samarqand State University, Samarqand, Uzbekistan
}

Email address:

bashirulla@mail.ru(S. Askarov)

${ }^{*}$ Corresponding author

\section{To cite this article:}

Shoikrom Askarov, Bashirulla Sharipov, Shokhista Saliyeva, Abdulaziz Mavlyanov, Solizhon Srazev, Tuchi Toshboev. Kinetics of Generation of Thermal Donors in Silicon of Stabilization of States of Fast-Diffusing Impurities. American Journal of Aerospace Engineering. Vol. 7, No. 1, 2020, pp. 1-5. doi: 10.11648/j.ajae.20200701.11

Received: June 3, 2019; Accepted: August 13, 2019; Published: January 8, 2020

\begin{abstract}
The paper reports that the intensity of generation and the concentration of low-temperature thermal donors (LTD) at $450^{\circ} \mathrm{C}$ in silicon, where fast diffusing impurities (FDI) are stabilized by means of binding them into electrically neutral chemically bound complexes with sulfur, are significantly lower compared to their intensity and concentration in reference samples of silicon doped with sulfur and pure reference samples. The "Kaiser model" states that the initial rate of generation of low-temperature thermal donors is proportional to biquadrate, and their maximum concentration is to the third degree of oxygen concentration. According to the Kaiser model of thermal donor generation, LTD represent predominantly stable tetrahedrons (i.e. $\mathrm{SiO}_{4}$ molecules). However, the Kaiser model does not take into account the possibility of interaction of oxygen with other impurities that might lead to the formation of electrically active centers. Based on the analysis of experimental results of $\mathrm{Si}<\mathrm{S}>$ samples subjected to heat treatment the authors recommend a revision of the principles of LTD in silicon in view of behavior of FDI, as they play a key role in the process of the formation of LTD. Thus, in the present paper the authors effectively are attempting to shed light on the anticipated role of impurity centers with deep levels in the process of formation of thermal donors.
\end{abstract}

Keywords: Silicon, Oxygen, Sulfur, Thermal Donors (LTD), Fast Diffusing Impurities (FDI), Electrically Neutral Chemically Bound Molecules

\section{Introduction}

It's well known that the concentration of oxygen in the single-crystalline silicon grown by the Czochralski in dustrial technique, reaches up to $\sim 1,5 \times 10^{18} \mathrm{~cm}^{-3}$ and that in most cases largely surpasses the concentration of the dopant impurities. Oxygen tends to be the most complex impurity in silicon to forecast its behavior. The oxygen dissolved in silicon virtually does not affect the electrical conductivity of the material. However, during growth of silicon single crystals and manufacture of various semiconductor devices based on single crystalline silicon, when crystals are subjected to prolonged heat treatment in the temperature range of $350-500^{\circ} \mathrm{C}$, the oxygen dissolved in the material rearranges, which is accompanied by the generation of lowtemperature thermal donors (LTD) [1-6].

Thermal donors significantly influence electro-physical parameters of silicon, such as electrical conductivity, lifetime of minority charge carriers, and the Hall mobility. Thus, in view of the fact that the initial rate of generation of LTD is proportional to biquadrate, and their maximum concentration is to the third degree of oxygen concentration, the authors in the study [7] had proposed the model of thermal donor generation kinetics widely known as "Kaiser model". According to the Kaiser model of thermal donor generation, LTD represent predominantly stable tetrahedrons (i.e. $\mathrm{SiO}_{4}$ 
molecules). The generation LTD in silicon allegedly leads to the formation of deep donor level centers and an array of shallow donor levels. According to various bibliographical sources they incidentally represent effective donor depth of $E_{c}-(0,13 \div 0,16)$ and $E_{c}-(0,033 \div 0,05)$ eV [3, 8-10]. In this sense, the deep donor level of $\mathrm{E}_{\mathrm{c}}-0,16 \mathrm{eVby}$ a number of authors was attributed to the generation of $\mathrm{SiO}_{4}$ complexes, whereas a system of shallow donor levels is allegedly attributed to oxygen - silicon polymers containing more than four oxygen atoms. It's worth noting that the Kaiser model is pertinent only to the mechanism of formation of LTD, while wider explanation of its donor properties was proposed in the papers of a French scientist J. P. Suchet [11, 12]. According to J. P. Suchet, a single-charged $\mathrm{O}_{4}$ donor tends to be the most likely LTD source and thus represents an ion of a molecule, occupying a silicon vacancy and adjacent interstitials. Meanwhile, one of oxygen atoms of the $\mathrm{O}_{4}$ molecule is in the substitution state with effective charge of + 2e. Stabilization of the oxygen atom in this state is achieved due to the distributed negative charge of the three interstitial oxygen atoms surrounding it.

Unfortunately, in the process of revising a model that would describe the mechanism of formation of low temperature thermal donors, Kaiser and et al. did not take into account the possibility of interaction of oxygen with other impurities that might lead to the formation of electrically active centers. Perhaps, at the time of publication of their research paper, they were not familiar with the results of the studies [13, 14], where the authors notesignificant acceleration of the generation of LTD as concentration of small acceptor impurities (Al, B, Ga) increases. Later, this issue was analyzed more thoroughly by authors in research paper [15], where the effect of a shallow donor impurity on kinetics of the generation of LTD in silicon was also studied. No effect of a shallow phosphorus donor impurity on the process of thermal donor generation was revealed, whereas significant acceleration and increase in the concentration of thermal donors was observed only in the presence of high concentration of boron acceptor impurity.

The anticipated role of impurity centers with deep levels in the process of formation of thermal donors is well discussed in the studies $[16,17]$. Such assumptions were made based on experimental evidence of the increase of the lifetime of minority charge carriers $\tau$ as the duration of annealing of silicon crystals increases. Simultaneously with an increase in $\tau$ after annealing at $450^{\circ} \mathrm{C}$, the authors in the study [17] report occurrence of multiple additional absorption bands in the wavelength range of 9-30 $\mu \mathrm{m}$, which the authors interpret as the result of absorption at different donor complexes.

Based on the above deviation from the Kaiser model in regards to dynamics of change of concentration of shallow and deep acceptor impurities, as well as the phenomena of appearance of additional electrically active centers in silicon samples annealed at $450^{\circ} \mathrm{C}$, the authors in the study [18] put forward a new hypothesis about the nature and mechanism of the formation of the low temperature thermal donors. According to the model they had proposed, oxygen plays a significant role in the formation of LTD. In contrast to the Kaiser model of thermal donor generation mechanism proposed by authors in [18], oxygen occupies a position in the silicon lattice site, whereby two extra electrons are released. In order for oxygen to manifestits donor properties, at least two vacancies are required. The first vacancy is required to transfer the oxygen atom in the state of substitution, and the other to stabilize it in the position of substitution (binding one of its valence electrons). Instead of a nearby vacancy, any adjacent acceptor-type impurity, such as boron, aluminum, as well as an impurity that generates deep levels (copper, iron, gold) can participate in the formation of a donor center. In general, the single-charge donor formed in this case can be represented as follows: $\mathrm{O}_{\mathrm{Si}}^{2+} \mathrm{A}$.

\section{Research Objectives and Tasks}

Apparentlya number of important factors were not taken by authors into consideration when building the hypothesis about the nature and mechanism of formation of thermal donors in silicon in the papers $[17,18]$. In our opinion the following significant factors should have been taken into account:

i. In order for a moleculetype - $\mathrm{O}_{\mathrm{Si}}^{2+} \mathrm{A}$ to be formed, a mere vacancy occurrence near oxygen will not be sufficient. Also migration of shallow acceptor impurities toward this vacancy will be necessary. It's worth noting that the diffusion coefficient of small acceptor impurities in the temperature range of thermal donor generation in silicon is extremely low. This reduces the likelihood of $\mathrm{O}_{\mathrm{Si}}^{2+} \mathrm{A}$ - type complex formation.

ii. The acceptor impurities that form deep levels in silicon are quite mobile as they diffuse through the dissociative mechanism. However, the maximum concentration of substitution centers for copper or iron in silicon does not exceed $5 \times 10^{14} \mathrm{~cm}^{-3}$, which is significantly lower than the concentration of LTD. In addition, in research papers $[16,17]$, the assumption about the possible role of impurity centers with deep levels in the process of thermal donor generation was made based on the results of a study of the effect of heat treatment in the temperature range of $350-500^{\circ} \mathrm{C}$ on the lifetime of minority charge carriers in silicon without a specific indication of the type of impurity centers with deep levels.

On this point, the effects of quenchedthermal donors (QTD) (formed in the process of quenching after high-temperature annealing of silicon crystals) on kinetics of the generation of thermal donors were investigated in the study [19]. QTD are most likely associated with the activation of uncontrolled, fast-diffusing impurities (FDI) in the bulk of silicon in the process of high-temperature annealing. Based on a comparative analysis of the results of studying the electrical parameters of silicon samples saturated with QTD and the initial silicon, depending on the duration of thermal 
annealing of crystals at $450^{\circ} \mathrm{C}$, a significant increase in the generation of LTD in silicon crystals containing QTD was found. Various nature FDI are involved in the formation of QTD, therefore the effect of increasing the generation of LTD in silicon saturated with QTD is the result of collective actions of a number of FDI.

To clarify the role of a particular fast-diffusing impurity in the study [20], the authors investigated the effect of manganese, iron and chromium on the kinetics of thermal donor generation in silicon. It was revealed that for each impurity there is a certain temperature range within which it significantly increases the generation of thermal donors in silicon, in particular, for iron, the generation of thermal donors is characterized by a range of $300-400^{\circ} \mathrm{C}$, while for manganese and chromium this interval is in the range of 350 $450^{\circ} \mathrm{C}$ and $400-500^{\circ} \mathrm{C}$, respectively. Based on the analysis of research results by authors in the research [20], it was suggested that the fast diffusing impurities participate in thermal donor constructions as active centers responsible for donor states.

Here, a natural question arises as to how the rate of generation of thermal donors will change if we stabilize the state of fast-diffusing impurities in the silicon crystal lattice at temperatures higher than the range of temperatures needed for thermal donor generation. In order to stabilize the state of fast diffusing impurities in the crystal lattice of silicon one needs to ensure formation of electrically neutral chemical bonds between them and sulfur [21, 22]. It's important to point out that for each specific fast diffusing impurity there is a certain temperature $T_{e f f}$, at which they most effectively interact with sulfur. $T_{\text {eff }}$ for all studied fast diffusing impurities is significantly higher than the temperature range required for the generation of thermal donors in silicon [23, 24].

In this regard, the main objective of the research is to investigate the kinetics of thermal donor generation in silicon in times of stabilization of fast diffusing impurity states in the crystal lattice by means of forming electrically neutral chemically bound complexes with sulfur.

\section{Experiment}

\subsection{Experimental Technique}

The silicon doping with sulfur was performed from gas phase in sealed quartz ampoules previously cleaned with solution of $\mathrm{HCl}: 3 \mathrm{HNO}_{3}$. Boron-doped single crystalline silicon sample with a specific resistance $\rho=10 \Omega \cdot \mathrm{cm}$, grown by Czochralski technique with concentration (infrared determined) of active oxygen $\sim 5 \times 10^{17} \mathrm{~cm}^{-3}$, was used as starting material. Samples were placed in an ampoule together with high purity sulfur as diffusion source.

The vapor pressure of sulfur was determined by the diffusion temperature and the weight of sulfur in the ampoule. The mass of sulfur was determined in the approximation of an ideal gas, taking into account the volume of ampoules. The vapor pressure in the doping process was 1 bar.
The diffusion doping was performed at a temperature of $1250^{\circ} \mathrm{C}$ for 100 hours. After the diffusion process, the samples were quenched by dropping the ampoules into cold water. Electrical measurements were performed to determine the resistivity $(\rho)$ and the Hall constant of the samples.

\subsection{Experimental Results}

Measurement of the electrical parameters of silicon samples, immediately after diffusion doping with sulfur, showed that the crystals were overcompensated and the samples were characterized by $n$ - type conductivity with $\rho=$ $8,22 \Omega \cdot \mathrm{cm}$. Shortly thereafter, some $\mathrm{Si}<\mathrm{S}>$ samples were subjected to subsequent heat treatment at a temperature of $880^{\circ} \mathrm{C}$. The choice of temperature was not random, rather it was pre-determined as it corresponds to the temperature of the most effective interaction of sulfur with chromium, which is the lowest among the temperatures of the most effective interaction of sulfur with iron $\left(910^{\circ} \mathrm{C}\right)$ and copper $\left(920^{\circ} \mathrm{C}\right)$. Chromium, iron and copper migrate into the bulk of silicon in the form of uncontrolled fast diffusing impurities [25, 26].

Measurement of the electrical parameters of $\mathrm{Si}<\mathrm{S}>$ samples subjected to heat treatment at $880^{\circ} \mathrm{C}$ for one hour showed that the entire electroactive portion of sulfur, having effectively formed electrically neutral chemically bound complexes with uncontrolled fast-diffusing impurities, is believed to be electrically neutralized and the crystals acquired starting material parameters.

In order to study the kinetics of thermal donor generation process, samples of $\mathrm{Si}<\mathrm{S}>$ subjected to heat treatment at a temperature of $880^{\circ} \mathrm{C}$, as well as reference samples of $\mathrm{Si}<\mathrm{S}>$ (i.e., crystals doped with sulfur, but not subjected to additional annealing at $880^{\circ} \mathrm{C}$ ) as well as $\mathrm{Si}$ (starting silicon samples, subjected to heat treatment at $880^{\circ} \mathrm{C}$ ) were subjected to long heat treatment at $450^{\circ} \mathrm{C}$.

After each heat treatment cycle, the electrical parameters of the samples were measured (Table 1). Based on the results in Table 1, it's clear that already after 10 hours of annealing at $450^{\circ} \mathrm{C}$, the control $\mathrm{Si}$ samples became overcompensated and got $n$ - type conductivity. Further increase in the duration of annealing leads to monotonous decrease in $\rho$. The phenomenon of monotonous decrease of $\rho$ as the duration of annealing increases also occurred in reference $\mathrm{Si}<\mathrm{S}>$ samples, whereas as for the $\mathrm{Si}<\mathrm{S}>$ samples subjected to heat treatment at $880^{\circ} \mathrm{C}$, their $\rho$ increased, and the conductivity type did not change. The nature of change in the parameters of the samples is surely symptomatic of generation of thermal donors in all crystalline samples.

Based on solution of the electro-neutrality equations, taking into account the parameters of the samples, as well as the degree of ionization of deep sulfur levels and thermal donors, the authors determined the concentration of generated thermal donors after 150 hours of annealing at $450^{\circ} \mathrm{C}$. The calculations showed that the highest concentration of thermal donors is generated in reference starting silicon samples, where their concentration was up to $\sim 1,38 \times 10^{16} \mathrm{~cm}^{-3}$. In reference $\mathrm{Si}<\mathrm{S}>$ samples, the concentration of generated thermal donors somewhat 
decreased and was approximately $\sim 4,07 \times 10^{15} \mathrm{~cm}^{-3}$. The lowest concentration of generated thermal donors occurred in
$\mathrm{Si}<\mathrm{S}>$ samples subjected to thermal annealing and showed $~$ $1,33 \times 10^{15} \mathrm{~cm}^{-3}$.

Table 1. Parameters of the samples after heat treatment at $450^{\circ} \mathrm{C}$.

\begin{tabular}{|c|c|c|c|c|c|c|c|c|c|c|c|c|}
\hline \multirow{3}{*}{ Samples } & \multicolumn{12}{|c|}{ Duration of annealing, hours } \\
\hline & \multicolumn{2}{|c|}{$\mathbf{0}$} & \multicolumn{2}{|c|}{10} & \multicolumn{2}{|l|}{30} & \multicolumn{2}{|l|}{60} & \multicolumn{2}{|l|}{100} & \multicolumn{2}{|l|}{150} \\
\hline & type & $\rho, \Omega \cdot \mathrm{cm}$ & type & $\rho, \Omega \cdot \mathbf{c m}$ & type & $\rho, \Omega \cdot \mathrm{cm}$ & type & $\rho, \Omega \cdot \mathrm{cm}$ & type & $\rho, \Omega \cdot \mathrm{cm}$ & type & $\rho, \Omega \cdot \mathrm{cm}$ \\
\hline $\mathrm{Si}<\mathrm{S}>\mathrm{T}=880^{\circ} \mathrm{C}$ & $\mathrm{p}$ & 10,09 & $\mathrm{p}$ & 11,05 & $\mathrm{p}$ & 12,75 & $\mathrm{p}$ & 14,33 & $\mathrm{p}$ & 20,1 & $\mathrm{p}$ & 30,1 \\
\hline $\mathrm{Si}<\mathrm{S}>$ - reference & $\mathrm{n}$ & 8,22 & $\mathrm{n}$ & 4,23 & $\mathrm{n}$ & 3,53 & $\mathrm{n}$ & 2,62 & $\mathrm{n}$ & 2,09 & $\mathrm{n}$ & 1,95 \\
\hline $\mathrm{Si}-$ reference & $\mathrm{p}$ & 10,2 & $\mathrm{n}$ & 1,81 & $\mathrm{n}$ & 1,09 & $\mathrm{n}$ & 0,66 & $\mathrm{n}$ & 0,55 & $\mathrm{n}$ & 0,44 \\
\hline
\end{tabular}

\section{Discussion}

Tounderstand how the presence of sulfur impurity centers contributes to reducing the concentration of thermal donor generation, one needs to discuss the anticipated behavior of sulfur impurity centers and uncontrolled impurity centers in silicon. Unlike oxygen, sulfur in silicon diffuses through a dissociative mechanism, forming a solid substitution solution. As the result, the remaining two extra electrons contribute two deep donor levels to the silicon band gap. These two electrons, participating in the processes of charge exchange with acceptor centers of small impurities, compensate the material and it assumes $n$ - type conductivity. This naturally raises the question of whether a minor change in the parameters of $\mathrm{Si}<\mathrm{S}>$ reference samples in compare to $\mathrm{Si}$ reference samples might be due to decomposition of the $\mathrm{Si}-$ $\mathrm{S}$ solid solution during heat treatment at $450^{\circ} \mathrm{C}$ that is accompanied by a decrease in the concentration of electroactive sulfur centers, rather than the decrease in the concentration of generated thermal donors. However, this conclusion contradicts the results of investigations of the parameters of $\mathrm{Si}<\mathrm{S}>$ samples subjected to heat treatment at $880^{\circ} \mathrm{C}$, i.e. samples completely free of electroactive sulfur centers, whereas the reduction in the generation of thermal donors only intensifies.

Therefore, one can assume that the decrease in the concentration of generated thermal donors in $\mathrm{Si}<\mathrm{S}>$ crystals may well have been caused by the stabilization of the states of uncontrolled impurity centers responsible for the formation of thermal donors during the heat treatment of crystals at $880^{\circ} \mathrm{C}$. It is well known from the research [19] that when uncontrolled impurity centers in silicon are in a loosely stabilized state in the form of QTD, they tend to decay even at temperatures of $\mathrm{T}<300^{\circ} \mathrm{C}$. Almost all elements of the periodic table could be viewed as uncontrolled impurities. However, not all of them are believed to have a significant impact on the process of thermal donor generation. One can exclude from this list all elements of the main group of the periodic table outright. Having allegedly dissolved in the crystal lattice of silicon in the form of substitution centers, they are believed to be stable (as sulfur is), in the temperature range of thermal donor generation. As for the elements of the non-basic group of the periodic table, such as lanthanides and actinides, we can also exclude them from this list, since their total concentration is extremely low than the concentration of generated thermal donors in silicon. So far only transition metals remain, whose behavior in silicon has been well studied. Transition metals diffuse in silicon through a dissociative mechanism, creating both centers of substitution and interstitial type. Meanwhile, the substitutional types of transient metals introduce a number of deep acceptor levels into the forbidden band, while interstitial centers introduce extremely deep donor levels. In addition, an interstitial center in the crystal lattice of silicon is extremely unstable. Therefore, such centers in silicon might eventually be responsible for the generation of thermal donors and quenched donors alike. Virtually all transition metals in silicon can be attributed to fast diffusing impurities. In the course of diffusion doping, the concentration of fast diffusing impurities increases relative to the concentration of uncontrolled impurities. An increase in the concentration of fast diffusing impurities largely contributes both to the increase in the rate and concentration of generated thermal donors [20]. On the other hand, the stabilization of fast diffusing impurities at temperatures higher than the temperature range of generation of low temperature thermal donors is accompanied by a decrease in both the rate and the concentration of thermal donors.

\section{Conclusion}

Having analyzed the results obtained during experiments, the authors came to believe that the decrease in the concentration of generated thermal donors in $\mathrm{Si}<\mathrm{S}>$ samples, both subjected to heat treatment at $880^{\circ} \mathrm{C}$, and reference samples during heat treatment at $450^{\circ} \mathrm{C}$, was largely due to the presence of sulfur impurity centers in the crystal lattice.

It should be noted that the formation of chemically bound sulfur complexes with fast diffusing impurities takes place even in the process of sharp quenching. This is evidenced by a decrease in the resistivity of overcompensated sulfur-doped silicon samples in the initial stage after diffusion annealing in the temperature range of $600 \div 1000^{\circ} \mathrm{C}$. Owing to partial association of uncontrolled fast diffusing impurities with sulfur in the process of quenching of reference sulfur-doped silicon samples, the concentration of the generated thermal donors decreases.

The results of these studies lead us to conclude that fast diffusing impurities participate in low temperature thermal donor generation as active centers responsible for donor states introduced by thermal donors in the silicon band gap. As for the mechanisms of formation of thermal donors and its principal model in silicon, this issue currently is investigated 
and will be the subject of further publications.

\section{References}

[1] C. S. Fuller, J. A. Ditzenberger, N. B. Hanny, E. Buehler Resistivity Changes in Silicon Induced by Heat Treatment // Phus. Rev. 1954. V. 96. №3. P. 833.

[2] W. Kaiser, P. H. Keck, C. F. Lange Infrared Absorption and Oxygen Content in Silicon and Germanium // Phus. Rev. 1956 V. 101. №3. P. 1264-1268.

[3] C. S. Fuller, R. A. Logan, N. B. Hanny Effect of Heat Treatment upon the Electrical Properties of Silicon Crystals // J. Appl. Phys. 1957. V. 28. №12. P. 1427-1436.

[4] W. Kaiser Electrical and Optical Properties of Heat-treated silicon // Phus. Rev. 1957. V. 105. №6. P. 1751-1756.

[5] R. A. Logan, A. J. Peters Diffusion of Oxygen in Silicon // J. Appl. Phys. 1957. V. 28.№7. P. 819-820.

[6] H. J. Hrostowski, R. H. Kaiser Infrared Spectrum of Heat Treatment Centers in Silicon // Phys. Rev. Lett. 1958. V. 1. №6. P. 199-200.

[7] W. Kaiser, H. L. Frisch, H. Reiss Mechanism of the Formation of Donors States in Heat - Treated Silicon // Phus. Rev. 1958. V. 112.№5. P. 1546-1554.

[8] F. J. Morin, J. P. Maita, R. G. Shulman, N. B. Hanny Impurity Levels in Silicon // Phus. Rev. 1954. V. 96. №3. P. 883.

[9] V. N. Mordkovich. O vliyanii kisloroda na provodimost kremniya [On influence of oxygen of silicon conductivity] // FTT [Solid State Physics]. 1964. V. 6. №3. P. 847-851.

[10] P. Gavortsevskiy, S. Gele, D. Mali, H. Rimani. Vliyaniye termoobrabotki monokristallov kremniya $s$ vysokim soderjaniyem kisloroda na elektrofizicheskiye parametri [On how thermal annealing of single crystalline silicon with high concentration of oxygen influences electro-physical parameters] // Svoystva legirovannyx poluprovodnikov [Properties of doped semiconductors]. M: Nauka, 1977. P. 203-210.

[11] J. P. Suchet Sur le role de I'oxygene dans les crictaux de silicium // J/Chim. Phus. 1961. V. 58. P. 445-463.

[12] J. P. Suchet. Fizicheskaya himiya poluprovodnikov [Physical Chemistry of Semiconductors]. M.: Metallurgy, 1969, 105 pgs.

[13] C. S. Fuller, F. H. Doleiden Interaction between Oxygen Acceptor Elements in Silicon // J. Appl. Phus. 1958. V. 29. № 8. P. $1264-1265$.
[14] C. S. Fuller, F. H. Doleiden, K. Wolfstirn Reactions of Group III Acceptors with Oxygen in Silicon Crystals // J. Phus. Chem. Solids. 1960. V. 13. P. 187-203.

[15] V. V. Batavin, E. A. Salnık. Vluanie aktseptorov na generatsiyu termodonorov $v$ kremnil, soderjaem kıslorod [Influence of acceptors on generation of thermal donors in oxygen-containing silicon]// Elektron. Tehnıka. Ser. VI. Materialy [Electron. Technology]. Ser. VI. Materials. 1980. №5. P. 42-45.

[16] K. Graff, H. Pieper, G. Goldbach Carrier Lifetime Doping of $p$ -type Silicon by Annealing processes // Semiconductor Silicon 1973 / Eds Huff H. R., Burgess R. R. P. 170-178.

[17] K. Graff, H. Pieper The Carrier Lifetime of Heat Treated Silicon Crystals // J. Electron. Mater. 1975. V. 4. № 2. P. $281-$ 298.

[18] D. Helmriech, E. Sirtl Oxygen in Silicon: a Modern View // Semiconductor Silicon 1977 / Eds Huff H. R., Sirtl E. P. 626635 .

[19] M. K. Bahadyrhanov, Sh. I. Askarov, N. Norqulov, S. N. Srajev 1994. V. 20, P. 36-41.

[20] M. K. Bahadyrhanov, Sh. I. Askarov, N. Norqulov, S. N. Srajev FTP [Phys. Tech. of Semicond.], V. 29, P. 1396-1401.

[21] M. K. Bakhadihanov, Sh. I. Askarov, N. Norkulov, Phys, Stat, Sol (a), 1994, p. 339.

[22] M. K. Bahadyrhanov, Sh. I. Askarov, N. Norqulov, S. N. Srajev Neorganicheskle materialy [Nonorganic materials]. 1992. V. 28, P. 1606-1608.

[23] M. K. Bahadyrhanov, Sh. I. Askarov, N. Norqulov, S. N. Srajev Neorganıcheskie materialy [Nonorganic materials]. 1996. V. 32, P. 15-21.

[24] M. K. Bahadyrhanov, Sh. I. Askarov, N. Norqulov, S. N. Srajev Neorganıcheskie materialy [Nonorganic materials]. 1996. V. 32, P. 647-649.

[25] G. W. Ludwig and H. Woodbury. Elektronnyl spınovy rezonans $v$ poluprovodnikah [Electron spin resonance in semiconductors]. MIR, M. 1964, P. 148.

[26] A. A. Lebedev, N. A. Sultanov, FTP [Phys and Tech. of Semicond.], 1971, V. 13, P. 1906-1912.

[27] Sh. Askarov, B. Sharipov, S. Srazhev, T. Toshboev, Sh. Saliyeva. Impurity States of Transition Group Elements in Silicon Lattice in the Process of Their Interaction with Sulfur //American Journal of Physics and Applications, June 14, 2018; 6 (3); 76-79. 